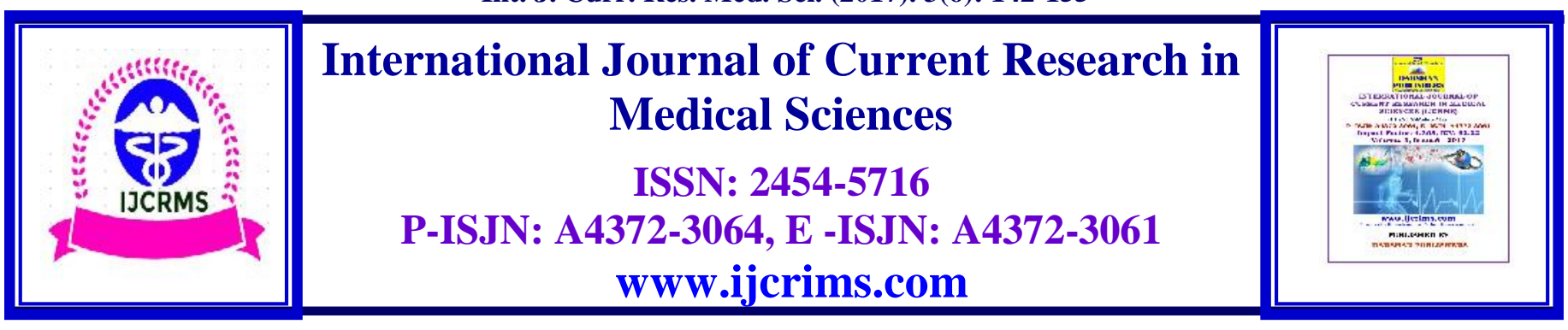

\title{
The combination of phacoemulsification surgery and intravitreal triamcinolone injection in patients with cataract and diabetic macular edema
}

\author{
Khedr M M1, Ghali A $\mathrm{A}^{2}$ and Gad $M \mathrm{~A}^{3}$ \\ ${ }^{1}$ Ophthalmology department -Faculty of medicine, Al-Azhar University (Cairo). \\ 2 Ophthalmology department- Faculty of medicine, Al-Azhar University (Damietta). \\ ${ }^{3-}$ Ophthalmology department- Faculty of medicine, Al-Azhar University (Damietta).
}

\begin{abstract}
Purpose: To assess the safety and efficiency of combined phacoemulsification and intra-vitreal triamcinolone injection in diabetic patients with cataract and diabetic macular edema.

Patient and methods: This prospective study included 25 eyes of 20 diabetic patients with visually significant cataract and coexisting diabetic macular edema (DME) attending the outpatient clinic of Al-Azhar University hospital (Damietta) during the period from June 2016 to January 2017.

All patients were undergoing phacoemulsification surgery followed by intravitreal injection of $4 \mathrm{mg}$ triamcinolone acetinoide.

Results: Statistically significant improvement was detected in BCVA and (central macular thickness) CMT. Preoperative BCVA ranged from 0.05 to 0.20 with the mean \pm SD of $0.094( \pm 0.039)$. At the $1^{\text {st }}$ week postoperative, BCVA ranged from 0.20 to 0.30 with a mean of $0.260( \pm 0.050)$. At the $6^{\text {th }}$ week postoperative, the BCVA ranged from 0.10 to 0.60 with a mean of $0.396( \pm 0.145)$. Finally, at $3^{\text {rd }}$ month postoperative, the BCVA ranged from 0.10 to 0.60 with a mean of $0.416( \pm 0.149)$.

Preoperative CMT ranged from $321 \mu \mathrm{m}$ to $805 \mu \mathrm{m}$ with mean $\pm \mathrm{SD}$ of $489.04( \pm 120.51) \mu \mathrm{m}$. At $6^{\text {th }}$ week postoperative CMT ranged from $119 \mu \mathrm{m}$ to $331 \mu \mathrm{m}$ with a mean of $239.48( \pm 48.88) \mu \mathrm{m}$. At $3^{\text {rd }}$ month postoperative CMT ranged from $162 \mu \mathrm{m}$ to $431 \mu \mathrm{m}$ with a mean of $243.68( \pm 62.78) \mu \mathrm{m}$.

Conclusions: Intravitreal triamcinolone can be combined safely and easily with of phacoemulsification surgery in patients with visually significant cataract and diabetic macular edema and the improvement in the BCVA and diabetic macular edema was significant.
\end{abstract}

Keywords: Phacoemulsification, Diabetic macular edema, Triamcinolone

\section{Introduction}

Diabetes causes visual impairment through diabetic retinopathy, a progressive disease of the retinal microvasculature (1). Diabetic macular edema is the main cause of visual impairment in diabetic patients (2). It is characterized by intraretinal and subretinal accumulations of fluid, 
resulting principally from retinal vascular leakage (3).

Phacoemulsification is used to restore vision in patients whose vision has become cloudy from cataracts. Phacoemulsification is procedure in which the lens clouded by a cataract is broken up by ultrasound, irrigated, and suctioned out. Most cataract surgery today is performed using phacoemulsification (4). Changes in central macular thickness occur after uncomplicated phacoemulsification either in diabetic or nondiabetic. Rate and range of increased central macular thickness is more in diabetic especially patients already have diabetic maculopathy or high central macular thickness preoperative (5). Also, cataract surgery in patients with diabetic retinopathy is associated with an increased risk of a number of problems including uveitis, posterior capsule opacity, and anterior capsule phimosis (6).

Using OCT, transient and clinically insignificant changes in the macular thickness have been observed after uneventful phacoemulsification (7). FFA is useful in helping diagnosis of diabetic retinopathy; however it has increased risk with contraindications and adverse effects in some patients. OCT is superior to FFA in the diagnosis of CME in that it is easy to perform, safe, objective and quantifiable. Furthermore it was reported that OCT is more sensitive than FFA in detecting $\mathrm{CME}$ associated with retinal vein occlusion, age-related macular degeneration and diabetic retinopathy. They found that $\mathrm{CME}$ was missed by FFA in some cases but FFA has the upper hand in detecting another forms of diabetic retinopathy $(\mathbf{8})$.

Triamcinolone acetonide, is an intermediate acting corticosteroid suspension with a depot effect lasting up to 41 days in animal studies, inhibits or down regulates inflammatory mediators such as prostaglandins and vascular endothelial growth factor and reduces breakdown of the blood-retinal barrier (9).

Intravitreal injection of triamcinolone is an alternative for treating CME especially in patients with advanced cataract. Triamcinolone acetonide is a corticosteroid with anti-inflammatory and antiangiogenic properties (10).However, intravitreal triamcinolone injection is not without potential risks including transient rise in intraocular pressure (IOP), cataract progression, vitreous haemorrhage, retinal detachment, as well as endophthalmitis (11).

The aim of this study is to assess the safety and efficiency of combined phacoemulsification surgery and intravitreal triamcinolone injection in diabetic patients with cataract and diabetic macular edema.

\section{Patients and Methods}

This prospective study included 25 eyes of 20 diabetic patients with visually significant cataract and coexisting diabetic macular edema (DME) attending the outpatient clinic of Al-Azhar University hospital (Damietta) during the period from June 2016 to January 2017.

\section{Inclusion criteria:}

Diabetic Patients (type I or type II diabetes) who had visually significant cataract and coexisting diabetic macular edema demonstrated by optic coherence tomography (OCT).

\section{Exclusion criteria:}

1- Patient who refuse to participate in our study.

2- Dense cataract interfering with OCT study.

3- $\quad$ Previous ocular trauma or surgery.

4- History of either ocular hypertension or glaucoma.

5- Complicated cataract surgery.

6- Presence of significant media opacity other than cataract.

The age of patients in the present work ranged from 45 to 68 years; the mean age was 57.80 years with SD $( \pm 7.87)$ years. There were 5 males $(20.0 \%)$ and 20 females $(80.0 \%)$ with male to female ratio of $4: 1$. The duration of DM (years), ranged from 7 to 22 years, the mean duration was 14.16 years with $\mathrm{SD} \pm 4.34$ years. 
BCVA was recorded preoperative, after one week, six weeks and three months postoperative. CMT was recorded preoperative, after six weeks and three months postoperative. IOP was recorded preoperative, after one day, one week, six weeks and three months postoperative (PO).

preoperative BCVA ranged from 0.05 to 0.20 with the mean \pm SD of $0.094( \pm 0.039)$; the central macular thickness ranged from $321 \mu \mathrm{m}$ to $805 \mu \mathrm{m}$ with mean \pm SD of $489.04( \pm 120.51) \mu \mathrm{m}$; the preoperative intraocular pressure ranged from 14.0 to $17 \mathrm{mmHg}$ with the mean $\pm \mathrm{SD}$ of 14.0 $( \pm 1.44) \mathrm{mmHg}$.

Phacoemulsification was done by Constellation machine (Alcon, Forte Worth, TX, USA). Before surgery, all pupils were dilated with $1 \%$ tropicamide and $2.5 \%$ phenylephrine, also ocular sterilization with a drop of povidine iodine $5 \%$ was used. Cataract surgery was performed under local anesthesia (periocular or retro bulbar) \pm sedation.

All surgeries were performed by one surgeon, clear corneal incision using keratome (2.4 or 2.8 ) was done, two side ports were made by MVR 20 gage or Super blade, formation of the anterior chamber by viscoelastic material, continuous circular curvilinear capsulorhexis performed under viscoelastic material started with bent insulin needle and completed with capsulorhexis forceps, hydro dissection and hydro delineation, Phacoemulsification done successfully for all patients. Stop and chop technique was the main technique used for phacoemulsification. Automated bimanual irrigation aspiration of cortical matter after removal of all nuclear quadrants was used, the capsular bag was inflated with viscoelastic material, after which the acrylic intraocular lens injected in the bag, and then removal of viscoelastic by automated I/A cannulas. Finally, hydration of the wound and the 2 paracentesis ports. At the completion of cataract surgery all patients were injected by $4 \mathrm{mgs}$ in 0.1 $\mathrm{ml}$ of triamcinolone acetonoide via the infera temporal pars plana $3.5 \mathrm{~mm}$ from limbus. The injection was directed into the inferior vitreous cavity to reduce the incidence of visually disturbing floaters post-operatively and was given inferior to the temporal corneal tunnel to avoid anterior chamber shallowing during scleral penetration of the needle.

Recording the PHACO power and time was done to exclude cases with prolonged phaco power and time. Eyes that had any intraoperative or postoperative complications were excluded from the study.

After the operation all patients were received the same standard medications for 4 weeks, consisting of a combination of steroid (Prednisolone acetate 1\%) and antibiotic (Moxifloxacin 0.5\%) eye drops beginning with five times daily, and tapered gradually.

Patients were examined 1 day, 1 week, 2 weeks, 2 months and 3 months after surgery. The response to treatment was monitored functionally by BCVA assessment by Snellen chart then converted to Log MAR and anatomically measuring the central macular thickness by OCT at $6^{\text {th }}$ week and $3^{\text {rd }}$ month. Biomicroscopic examinations and IOP monitoring were performed on each visit. Topical antiglaucoma treatment was initiated if IOP was more than $21 \mathrm{mmHg}$.

Data were analyzed using Statistical Program for Social Science (SPSS) version 18.0. Quantitative data were expressed as mean \pm standard deviation (SD). Qualitative data were expressed as frequency and percentage.

\section{Results}

Statistically significant improvement was detected in BCVA and CMT. Preoperative BCVA ranged from 0.05 to 0.20 with the mean \pm SD of 0.094 $( \pm 0.039)$. At the 1 st week postoperative, BCVA ranged from 0.20 to 0.30 with a mean of 0.260 $( \pm 0.050)$. At the 6 th week postoperative, the BCVA ranged from 0.10 to 0.60 with a mean of 0.396 ( \pm 0.145$)$. Finally, at 3rd month postoperative, the BCVA ranged from 0.10 to 0.60 with a mean of $0.416( \pm 0.149)$.

Preoperative CMT ranged from $321 \mu \mathrm{m}$ to 805 $\mu \mathrm{m}$ with mean \pm SD of $489.04( \pm 120.51) \mu \mathrm{m}$. At $6^{\text {th }}$ week postoperative CMT ranged from $119 \mu \mathrm{m}$ 
to $331.0 \mu \mathrm{m}$ with a mean of $239.48( \pm 48.88) \mu \mathrm{m}$. At $3^{\text {rd }}$ month postoperative CMT ranged from 162 $\mu \mathrm{m}$ to $431 \mu \mathrm{m}$ with a mean of $243.68( \pm 62.78)$ $\mu \mathrm{m}$.

The preoperative IOP ranged from 14.0 to 17 $\mathrm{mmHg}$ with the mean $\pm \mathrm{SD}$ of $14.0( \pm 1.44)$
$\mathrm{mmHg}$. At the $1^{\text {st }}$ week postoperative IOP ranged from 12 to $28 \mathrm{mmHg}$ with mean $\pm \mathrm{SD}$ of 15.96 $( \pm 4.51) \mathrm{mmHg}$. At $6^{\text {th }}$ weeks postoperative IOP ranged from 11 to $15 \mathrm{mmHg}$ with a mean of 12.92 $( \pm 1.15) \mathrm{mmHg}$. At 3 months postoperative IOP ranged from 11 to $14 \mathrm{mmHg}$ with a mean of 12.36 $( \pm 0.95) \mathrm{mmHg}$.

Preoperative measurements

\begin{tabular}{|l|c|c|c|c|}
\hline & Minimum & Maximum & Mean & SD \\
\hline BCVA & 0.05 & 0.20 & 0.094 & 0.039 \\
\hline CMT & 321.00 & 805.00 & 489.04 & 120.51 \\
\hline IOP & 11.00 & 17.00 & 14.00 & 1.44 \\
\hline
\end{tabular}

Postoperative measurements in studied patients

\begin{tabular}{|l|c|c|c|c|c|}
\hline \multicolumn{2}{|l|}{ Postoperative } & Mean & SD & Minimum & Maximum \\
\hline One day & IOP & $18.0 \mathrm{mmHg}$ & 1.44 & $16.00 \mathrm{mmHg}$ & $21.00 \mathrm{mmHg}$ \\
\hline \multirow{3}{*}{ One week } & BCVA & 0.260 & 0.050 & 0.20 & 0.30 \\
\cline { 2 - 6 } & IOP & $15.96 \mathrm{mmHg}$ & 4.51 & $12.00 \mathrm{mmHg}$ & $28.00 \mathrm{mmHg}$ \\
\hline \multirow{3}{*}{ Six weeks } & BCVA & 0.396 & 0.145 & 0.10 & 0.60 \\
\cline { 2 - 6 } & CMT & $239.48 \mu \mathrm{m}$ & 48.88 & $119.00 \mu \mathrm{m}$ & $331.00 \mu \mathrm{m}$ \\
\cline { 2 - 6 } & IOP & $12.92 \mathrm{mmHg}$ & 1.15 & $11.00 \mathrm{mmHg}$ & $15.00 \mathrm{mmHg}$ \\
\hline Three months & BCVA & 0.416 & 0.149 & 0.10 & 0.60 \\
& CMT & $243.68 \mu \mathrm{m}$ & 62.78 & $162.00 \mu \mathrm{m}$ & $431.00 \mu \mathrm{m}$ \\
\cline { 2 - 6 } & IOP & $12.36 \mathrm{mmHg}$ & 0.95 & $11.00 \mathrm{mmHg}$ & $14.00 \mathrm{mmHg}$ \\
\hline
\end{tabular}

Statistically significant improvement in BCVA were detected when comparing postoperative values at one week, six weeks and three months to corresponding preoperative value. In addition, values at six weeks and three months were significantly improved when compared to values at one week post-operative. On other hand, values at three months revealed non-significant difference when compared to values at six weeks. When comparing post-operative values of CMT with pre-operative values, the values at six weeks and three months post-operative, were significantly decreased when compared to preoperative values. On the other hand, values at three months showed non-significant difference when compared to values at six weeks postoperative.

Regarding IOP, there was statistically significant increase of IOP at the first postoperative day and PO week when compared to preoperative values. Then, there was significant decrease at six weeks and three months when compared to preoperative values. In addition, there was significant decrease of IOP at one week, six weeks and three months when compared to first PO day. Also, there was significant decrease at six weeks and three months when compared to one week PO. Finally, there was significant decrease at 3 months when compared to values at six weeks. 
Int. J. Curr. Res. Med. Sci. (2017). 3(6): 142-155

Distribution of patients as regard to the response to the treatment

\begin{tabular}{|l|l|l|}
\hline & $\mathbf{N}$ & $\mathbf{\%}$ \\
\hline Improved & 23 & $92 \%$ \\
\hline Recurrence & 2 & $8 \%$ \\
\hline
\end{tabular}

As regard to the response to the treatment, 23 patient $(92 \%)$ showed good response and were improved in CMT and BCVA and this improvement was maintained till the end of this study, 2 patients (8\%) show good response at first and there were improvement in CMT and BCVA, but this improvement was not maintained till the end of the study and the patients showed recurrence of macular edema and deterioration of BCVA.

\section{Case no 1:-}

Sixty years old female patient with 10 years history of D.M, on insulin therapy presented with diminution of vision in right eye. There is no history of other systemic or ocular disease.

Pre-operative assessment reveals that her BCVA was 0.2 , IOP was $15 \mathrm{mmHg}$, anterior segment examination reveals significant nuclear cataract, fundus examination reveals mild NPDR (fig. 1A \&1B) with CSME.

Otherwise there are neither media opacities nor other ocular abnormalities. By OCT there is Cystoid macular edema, the CMT $=555 \mu \mathrm{m}$, no evidence of ERM (fig.1C \&1D).

Combined Phacoemulsification with intraocular lens (IOL) implantation-in bag-, and intravitreal triamcinolone injection through infero-temporal approach using $27 \mathrm{G}$ syringe was done.
In the first day post-operative IOP was $17 \mathrm{mmHg}$; anterior segment was quite with clear cornea, well-formed AC and the IOL in place. In posterior segment examination there`s triamcinolone particles scattered on vitreous and retina.

One week later, the BCVA was improved to 0.3, IOP was $14 \mathrm{mmHg}$, by anterior segment examination; there's clear cornea, well-formed $\mathrm{AC}$ and the IOL in place. Fundus exam: there's triamcinolone particles on retina.

At the 6th week post-operative, BCVA improved to 0.5 , IOP was $14 \mathrm{mmHg}$, anterior segment examination revealed clear cornea, well-formed $\mathrm{AC}$ and the IOL in place. By fundus exam; there`s dry macula. OCT was done, the OCT data showed that improved macular edema with the CMT improved to be $\sim 214 \mu \mathrm{m}$ (fig.1E \&1F).

At the 3rd month post-operative full ophthalmological examination, FFA and OCT were done which revealed that the BCVA was 0.5 , IOP was $14 \mathrm{mmHg}$. By anterior segment examination there's clear cornea, well-formed AC, IOL in place. Fundus exam revealed dry macula. The clinical data was correlated with FFA (fig. 1I \&1J) and OCT data which showed maintained dry macula with CMT slightly regressed to $\sim 232 \mu \mathrm{m}$ (fig. $1 \mathrm{G} \& 1 \mathrm{H}$ ). 
Int. J. Curr. Res. Med. Sci. (2017). 3(6): 142-155

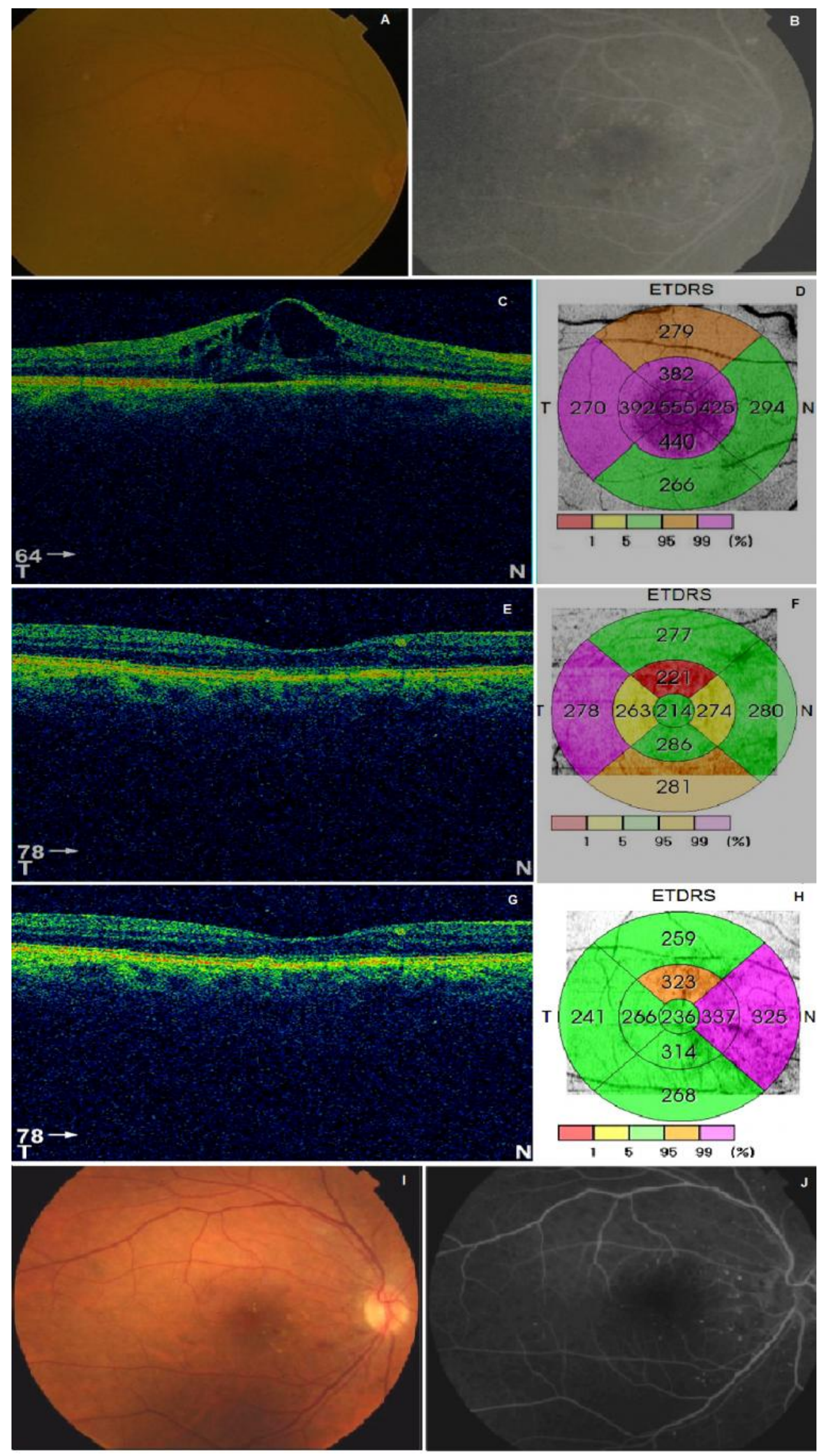


Figure (1): case 1. A- Pre-operative Colour fundus photo of the right eye showing manifestations of mild NPDR in the form of multiple micro aneurysms and flame shaped retinal hemorrhage with CSME. BFluorescein fundus angiography of the right eye showing blocked fluorescence corresponding to retinal hemorrhage in the colour fundus photography, hyperflourescent dots corresponding to the micro aneurysms, the macular area showing leakage duo to presence of macular edema. C- Pre-operative 3D-spectral domain OCT of the right eye showing multiple hypo-reflective spaces of cystoid macular edema with presence of subfoveal cyst. D- Pre operative macular thickness map showing increased macular thickness with the $\mathrm{CMT}=555 \mathrm{um} . \mathrm{E}-6^{\text {th }}$ week Post-operative OCT showing improvement of the macular edema. F- Macular thickness map at $6^{\text {th }}$ week post-operative showing central macular thickness $=214 \mathrm{um}$. G- $3^{\text {rd }}$ month postoperative OCT showing maintaining of the dry macula. H- Macular thickness map at $3^{\text {rd }}$ month postoperative showing central macular thickness $=230 \mathrm{um}$. I- $3^{\text {rd }}$ month post-operative Colour fundus photo showing improved macular edema. J- $3^{\text {rd }}$ month post-operative FFA showing improved macular edema.

\section{Case no 2:-}

58 years old female patient with 22 years history of D.M, on insulin therapy, hypertensive presented with diminution of vision in left eye. There is no history of other systemic or ocular disease.

Pre-operative assessment reveals that her BCVA was 0.05 , IOP was $12 \mathrm{mmHg}$, anterior segment examination reveals significant nuclear cataract, fundus examination reveals moderate NPDR (fig. 1A \&1B) with CSME. Otherwise there are neither media opacities nor other ocular abnormalities. By OCT there is Cystoid macular edema with SNRD, the CMT $=626 \mu \mathrm{m}$, no evidence of ERM (fig.1C \&1D).

Combined Phacoemulsification with intraocular lens (IOL) implantation-in bag-, and intravitreal triamcinolone injection through infero-temporal approach using $27 \mathrm{G}$ syringe was done.

In the first day post-operative IOP was $16 \mathrm{mmHg}$; anterior segment was quite with clear cornea, well-formed $\mathrm{AC}$ and the IOL in place. In posterior segment examination there`s triamcinolone particles scattered on vitreous and retina.
One week later, the BCVA was improved to 0.2, IOP was $18 \mathrm{mmHg}$, by anterior segment examination; there's clear cornea, well-formed $\mathrm{AC}$ and the IOL in place. Fundus exam: there`s triamcinolone particles on retina.

At the 6th week post-operative, BCVA improved to 0.3 , IOP was $15 \mathrm{mmHg}$, anterior segment examination revealed clear cornea, well-formed $\mathrm{AC}$ and the IOL in place. By fundus exam; there's improved CSME but there's increase in hard exudate. OCT was done, the OCT data showed that improved macular edema with the CMT improved to be $\sim 328 \mu \mathrm{m}$ (fig. $1 \mathrm{E} \& 1 \mathrm{~F}$ ).

At the 3rd month post-operative full ophthalmological examination, FFA and OCT were done which revealed that the BCVA was 0.2 , IOP was $14 \mathrm{mmHg}$. By anterior segment examination there's clear cornea, well-formed $\mathrm{AC}$, IOL in place. Fundus exam: there's CSME associated with increased area of hard exudate. The clinical data was correlated with FFA (fig. 1I $\& 1 \mathrm{~J}$ ) and OCT data which showed recurrence of macular edema with increase in CMT to $\sim 431$ $\mu \mathrm{m}$ (fig. $1 \mathrm{G} \& 1 \mathrm{H}$ ). 
Int. J. Curr. Res. Med. Sci. (2017). 3(6): 142-155

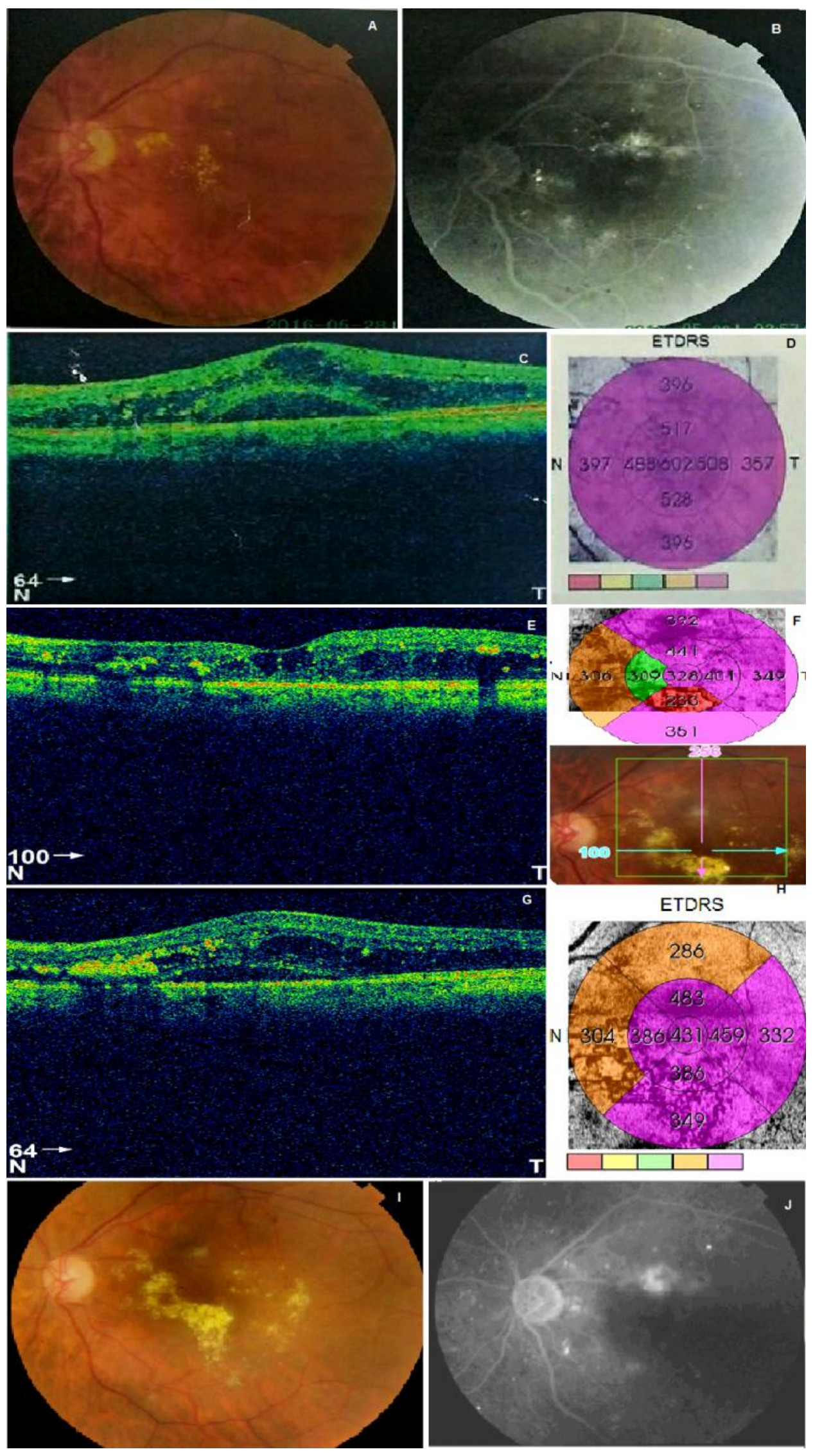


Figure (2): case 2. A- Pre-operative Colour fundus photo of the left eye showing manifestations of mild NPDR in the form of multiple micro aneurysms and flame shaped retinal hemorrhage and hard exudates with CSME. B-Fluorescein fundus angiography of the left eye showing blocked fluorescence corresponding to retinal hemorrhage and hard exudates in the colour fundus photography, hyperflourescent dots corresponding to the micro aneurysms, the macular area showing leakage duo to presence of macular edema. C- Pre-operative 3D- spectral domain OCT of the left eye showing dome shaped macula with presence of multiple hypo-reflective spaces of cystoid macular edema and SNRD. D-Pre operative macular thickness map showing increased macular thickness with the CMT $=555 \mathrm{um}$. E- $6^{\text {th }}$ week Post-operative OCT showing improvement of the macular edema with regaining of the foveal contour. F- Macular thickness map at $6^{\text {th }}$ week post-operative showing central macular thickness $=326 \mathrm{um}$. G- $3^{\text {rd }}$ month postoperative OCT showing recurrent macular edema. H- Macular thickness map at $3^{\text {rd }}$ month post-operative showing central macular thickness $=431 \mathrm{um}$. I\&J- $3^{\text {rd }}$ month post-operative Colour fundus photo and FFA showing recurrent macular edema with aggravated hard exudates.

\section{Case no 3:-}

63 years old male patient uncontrolled type II DM on insulin therapy for 12 years, hypertensive presented with blurred vision of his right eye.

Pre-operative assessment reveals that her BCVA was 0.05 , IOP was $16 \mathrm{mmHg}$, anterior segment examination reveals significant cataract, fundus examination reveals moderate NPDR (fig. 1A \&1B) with CSME. Otherwise there are neither media opacities nor other ocular abnormalities. By OCT there is Cystoid macular edema, the $\mathrm{CMT}=751 \mu \mathrm{m}$, no evidence of ERM (fig.1C \&1D).

Combined Phacoemulsification with intraocular lens (IOL) implantation-in bag-, and intravitreal triamcinolone injection through infero-temporal approach using $27 \mathrm{G}$ syringe was done.

In the first day post-operative IOP was $16 \mathrm{mmHg}$; anterior segment was quite with clear cornea, well-formed AC and the IOL in place. In posterior segment examination there`s triamcinolone particles scattered on vitreous and retina.
One week later, the BCVA was improved to 0.1, IOP was $18 \mathrm{mmHg}$, by anterior segment examination; there's clear cornea, well-formed $\mathrm{AC}$ and the IOL in place. Fundus exam: there`s triamcinolone particles on retina.

At the 6th week post-operative, BCVA improved to 0.2 , IOP was $15 \mathrm{mmHg}$, anterior segment examination revealed clear cornea, well-formed $\mathrm{AC}$ and the IOL in place. By fundus exam; there's improved CSME but there's residual edema (no marked improvement). OCT was done, the OCT data showed that improved macular edema with the CMT improved to be $\sim 461 \mu \mathrm{m}$ (fig. $1 \mathrm{E} \& 1 \mathrm{~F}$ ).

At the 3rd month post-operative full ophthalmological examination, FFA and OCT were done which revealed that the BCVA was 0.1 , IOP was $14 \mathrm{mmHg}$. By anterior segment examination there's clear cornea, well-formed $\mathrm{AC}$, IOL in place. Fundus exam: there's CSME associated with increased area of hard exudate. The clinical data was correlated with FFA (fig. 1I $\& 1 \mathrm{~J})$ and OCT data which showed persistence of macular edema with increase in CMT to $\sim 602$ $\mu \mathrm{m}$ (fig. $1 \mathrm{G} \& 1 \mathrm{H}$ ). 
Int. J. Curr. Res. Med. Sci. (2017). 3(6): 142-155
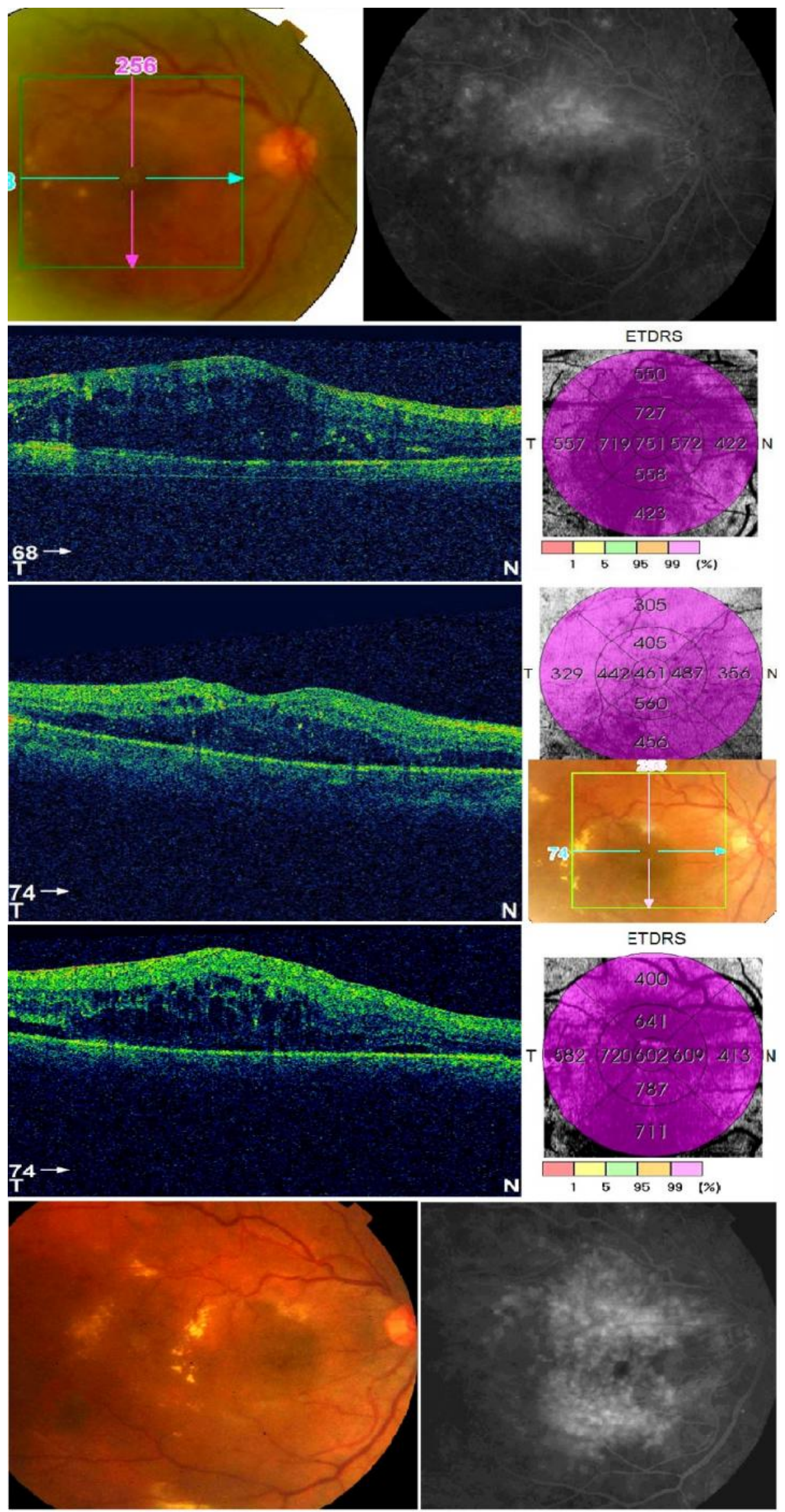
Figure (3): case 3. A- Pre-operative Colour fundus photo of the right eye showing manifestations of mild NPDR in the form of multiple micro aneurysms, flame shaped retinal hemorrhage and hard exudates with CSME. B- Fluorescein fundus angiography of the left eye showing blocked fluorescence corresponding to retinal hemorrhage and hard exudates in the colour fundus photography, hyperflourescent dots corresponding to the micro aneurysms, the macular area showing leakage of flower-beaten appearance duo to presence of cystoid macular edema. C- Pre-operative OCT of the right eye showing lost foveal contour and presence of multiple hypo-reflective spaces of cystoid macular edema. D- Pre operative macular thickness map showing increased macular thickness with the CMT $=751 \mathrm{um}$. E- $6^{\text {th }}$ week Post-operative OCT showing mild improvement of the macular edema. F- Macular thickness map at $6^{\text {th }}$ week postoperative showing central macular thickness $=461 \mathrm{um}$. G- $3^{\text {rd }}$ month post-operative OCT showing persistent macular edema. H- Macular thickness map at $3^{\text {rd }}$ month post-operative showing central macular thickness= $602 \mathrm{um} . \mathrm{I} \& \mathrm{~J}-3^{\text {rd }}$ month post-operative Colour fundus photo and FFA showing persistent macular edema with aggravated hard exudates.

\section{Discussion}

Diabetic macular edema is the most common cause of visual loss in diabetic patients. The pathogenesis of diabetic macular edema is multifactorial. It results from multiple biochemical and cellular changes that eventually cause leakage and exudation (1). A number of patient characteristics such as increasing age, female sex, duration of diabetes mellitus and poor glycemic control at the time of surgery and moderate to severe retinopathy have been found associated with poor prognosis after cataract surgery in diabetic patients (12).

This study conducted on 25 eyes of 20 patients attending the outpatient clinic of Al-Azhar University hospital (Damietta) during the period from June 2016 to January 2017. We assessed visual outcome and CMT after the combination of uncomplicated phacoemulsification surgery and intravitreal triamcinolone injection in patients with cataract and diabetic macular edema.

In this study all patients underwent phacoemulsification and in-the-bag intraocular lens implantation with a self-sealing corneal tunnel and intravitreal triamcinolone injection. $80 \%$ of our patients were female, the mean age was 57.80 years and the mean duration of diabetes mellitus was 14.16 years.

Several studies have shown that phacoemulsification can result in exacerbation of macular edema in diabetic patients. Khedr (2014), demonstrated that $20 \%$ of diabetic patient show increase in central macular thickness after uncomplicated phacoemulsification (5). Liu (2015), shows that uncomplicated phacoemulsification with intraocular lens implantation causes a significant increase in subclinical thickening in the region of the central macula in diabetic patients with mild to moderate NPDR at postoperative 1, 3 and 6 months (13).

Other studies have shown that there is no increase in risk of progression, suggesting that the risk is less with modern phacoemulsification techniques. Short-time phacoemulsification surgery with small self-sealed corneal incisions without iris trauma, and in-the-bag implantation of intraocular lenses, in general do not cause progression of diabetic retinopathy (14).

In this study the BCVA during the 3 months of follow-up period after a successful phacoemulsification with $4 \mathrm{mg}$ intravitreal triamcinolone injection was significantly higher than the initial BCVA.

When comparing postoperative values at one week, six weeks and three months to corresponding preoperative value, there was statistically significant increase of numerical values of BCVA at all postoperative measurements when compared to preoperative values. 
In addition, values at one week, six weeks and three months were significantly increased when compared to values at the first postoperative day. Also, values at six weeks and three months were significantly increased when compared to values at one week postoperative. On other hand, values at three months revealed non-significant difference when compared to values at six weeks.

There have been several previous studies evaluating the results of intravitreal injection of TA combined with phacoemulsification in diabetic patients with macular edema. Habib et al., (2005), evaluated the outcomes of $4 \mathrm{mg}$ of intravitreal triamcinolone injection at the time of cataract surgery in 18 eyes of 12 patients with diabetic foveal edema and found a statistically significant increase in BCVA with $50 \%$ of eyes achieving $6 / 12$ or better BCVA and $83 \%$ of eyes with no macular edema at 2 weeks (10). Lam et al., (2005), assessed the efficacy of phacoemulsification with $4 \mathrm{mg}$ intravitreal triamcinolone injection in 19 eyes of 15 diabetic patients with cataract and diabetic macular edema with a follow-up of 6 months and found that $58.8 \%$ of eyes showed improvement in BCVA of $>=2$ lines (15) . Ozgur et al., (2016), Show that the BCVA during the 6 months of follow-up period after a successful PHACO surgery with 4 $\mathrm{mg}$ intravitreal triamcinolone injection was significantly higher than the initial BCVA (16), But Ahmadabadi et al., (2010), reported injection of triamcinolone after phacoemulsification had no effect on visual acuity (17).

Anatomically, in this study, the central macular edema of patients who had phacoemulsification together with intravitreal triamcinolone injection showed reduction to a minimum CMT achieved at $6^{\text {th }}$ week and was sustained at 3 month.

When comparing postoperative values of CMT with preoperative values $($ mean $=489.04 \pm 120.51$ ), the values at six weeks postoperative (mean = $239.48 \pm 48.88)$ and three months postoperative (mean $=243.68 \pm 62.78)$, were significantly decreased with compared to preoperative values. On the other hand, values at three months showed non-significant difference when compared to values at six weeks postoperative.
Ozgur et al., (2016), demonstrated that: the CMT decreased from preoperative values with statistically significant reduction at all postoperative intervals until 6 months $(p<0.01)$. There was an average of $44.78 \%$ reduction in the mean CMT at the 2nd week and $34.67 \%$ reduction at the 6th month (16). Lam et al., (2005), reported that there's decrease in mean CMT from $449 \mu \mathrm{m}$ preoperatively to $321 \pm 148 \mu \mathrm{m}$ at 2 months postoperative follow-up (15).

In this study we have 2 eyes of 25 eyes ( $8 \%$ ) were found to have recurrence of macular oedema 3 months after PHACO and intravitreal triamcinolone injection.

Martidis et al., (2002), reported that recurrence of macular edema following intravitreal triamcinolone injection is not uncommon. In total, $37.5 \%$ of eyes were found to have recurrence of macular edema 6 months after intravitreal triamcinolone injection for refractory diabetic macular edema.

In this study there are three eyes (12\%) of 25 eyes developed an increased IOP of over $21 \mathrm{mmHg}$ at the $1^{\text {st }}$ week visit. None of these patients had pre existing raised intraocular pressure or were known steroid responders. The IOP was normalized by topical antiglaucomatous agents.

Studies investigating the efficacy of intravitreal triamcinolone injection have reported the prevalence of IOP elevations to be between $9 \%$ and $77 \%$. The wide range in prevalence may be because of varying definitions of IOP increase, triamcinolone concentration and considering time of increase in IOP (17).

Also, combining the two procedures reduces the patient's potential risk of endophthalmitis from two separate intraocular episodes to one, whilst at the same time offering improved patient convenience. The technique was simple adding very little time to the procedure and in this series there was no significant ocular morbidity (15).

In this study, all of our patients had diabetes mellitus and underwent uncomplicated cataract extraction in addition to intravitreal 
triamcinolone injection. We listed no cases of endophthalmitis. All the surgeries were performed in the operating room with full asepsis, lid speculum, proper draping of the patient's eyelashes and topical povidone preoperatively.

There are other treatment options such as direct argon laser photocoagulation applied to focally leaking micro-aneurysms and/or grid treatment applied to areas of diffuse macular edema results in a substantial reduction of the risk of visual loss in eyes with diabetic macular edema (18). There are also, intravitreal injections of antivascular endothelial growth factor (anti-VEGF) drugs or pars plana vitrectomy for DME. Ranibizumab and bevacizumab are the two main anti-VEGF drugs used commonly. Although ranibizumab has been recently approved by the United States Food and Drug Administration for the treatment of DME, it is expensive. Bevacizumab, which costs much less than ranibizumab, is commonly used (19).

The results of studies comparing intravitreal triamcinolone injection and intravitreal bevacizumab (IVB) in DME are controversial. Some studies found intravitreal triamcinolone injection more effective than IVB, some the same and some less effective. A metaanalysis shows that the group receiving intravitreal triamcinolone injection has a statistically significant improvement in BCVA than the group receiving IVB in the first 3 months. But the difference in BCVA was not observed at 6 months. Also the side effects of intravitreal triamcinolone injection such as elevation of IOP, cataract formation and risk of endophthalmitis cause limitations in their use (20).

DRCR-net study indicated that intravitreal steroid or ranibizumab injections combined with laser treatment have a superior effect on VA improvement than laser treatment alone in diabetic macular edema (21).

\section{Conclusion}

This study suggests that intravitreal triamcinolone can be given safely and easily at the time of phacoemulsification surgery in patients with visually significant cataract and diabetic macular edema.

We found that there is statistically significant improvement in the BCVA and diabetic macular edema, but frequent follow up of patients is important to detect recurrent and refractory cases to be managed probably and to manage IOP fluctuations.

\section{References}

1. Burgess P I, MacCormic I J, Harding S P, et al (2013): Epidemiology of diabetic retinopathy and maculopathy in Africa: a systematic review. Diabet Med.2013: 30(4): 399-412.

2. Gaudric A. \& Massin-Korobelnik P (1993): Diabetic maculopathy: classification, epidemiology, spontaneous outcome, treatment. Diabet Metab. 1993: 19:422-429.

3. Hamilton AMP, Ulbig MW, Polkinghorne P, et al (1996): Management of diabetic retinopathy. BMJ Publishing Group. Epidemiology of diabetic retinopathy; pp. 115.

4. Thevi T, Reddy SC, Shantakumar C (2014): Outcome of phacoemulsification and extracapsular cataract extraction: A study in a district hospital in Malaysia. Malays FAM Physician. 2014; 9(2): 41-47.

5. Khedr M (2014): Evaluation of central macular thickness changes after uncomplicated phacoemulsification in diabetic patients. Journal of American Sciences: 2014: 10(10); 153-156.

6. Kato S, Oshika T, Numaga J, et al (2001): Anterior capsular contraction after cataract surgery in eyes of diabetic patients. $\mathrm{Br} \mathrm{J}$ Ophthalmol; 2001 85:21-3.

7. Biro Z, Balla Z, Kovacs B (2008): Change of foveal and perifoveal thickness measured by OCT after phacoemulsification and IOL implantation. Eye,

2008: 22:8-12.

8. Jittpoonkuson T, Garcia PMT, Rosen RB (2010): Correlation between fluorescein angiography and spectral-domian optical coherence tomography in the diagnosis of 
cystoid macular edema.Br J Ophthalmol.94:1197-1200.

9. Shamsi Hanan N, Jluwi S Masaud, Nicola G Ghazi (2013): Diabetic macular edema: New promising therapies. World J Diabetes. Dec 15; 4(6): 324-338.

10. Habib M.S., Cannon P., Steel D.H.W (2005): The combination of intravitreal triamcinolone and phacoemulsification surgery in patients with diabetic foveal oedema and cataract. BMC Ophthalmol. 5:15.

11. Bakri SJ \& Beer PM (2003): The effect of intravitreal triamcinolone acetonide on intraocular pressure. Ophthalmic Surg Lasers Imaging; 34: 386-390.

12. Ryan Lee, Tien Y. Wong, Charumathi Sabanayagam (2015): Epidemiology of diabetic retinopathy, diabetic macular edema and related vision loss. Eye (Lond); 2: 17.

13. Liu J, Jones RE, Zhao J, et al (2015): Influence of Uncomplicated Phacoemulsification on Central Macular Thickness in Diabetic Patients: A MetaAnalysis. PLoS ONE 10(5): journal.pone.0126343.

14. Chen Xiao-Yong, Wen-Jun Song, HongYuan Cai, Lin Zhao (2016): Macular edema after cataract surgery in diabetic eyes evaluated by optical coherence tomography. Int J Ophthalmol; 9(1): 81-85.

15. Lam DS, Chan CK, Mohamed S., et al (2005): Phacoemulsification with intravitreal triamcinolone in patients with cataract and coexisting diabetic macular edema: a 6-month prospective pilot study. Eye (Lond); 19(8):88590.

16. Ozgur, Ozlen Rodop., et al (2016): The Combination of Phacoemulsification Surgery and Intravitreal Triamcinolone Injection in Patients with Cataract and Diabetic Macular Edema. Saudi Journal of Ophthalmology 30.1: 33-38.

17. Ahmadabadi H.F., Mohammadi M., Beheshtnejad H., et al (2010): Effect of intravitreal triamcinolone acetonide injection on the central macular thickness in diabetic patients having phacoemulsification. J Cataract Refract Surg; 36:917-922.

18. Park Y. G., Kim E. Y., and Roh Y. J., (2014): "Laser-based strategies to treat diabetic macular edema: history and new promising therapies," Journal of Ophthalmology, vol. 2014, Article ID 769213, 9 pages.

19. Ozkiris A (2009). Intravitreal bevacizumab (Avastin) for primary treatment of diabetic oedema. Eye; 23:616-620.

20. Zhang Xiao-Ling, Chen Jian, Zhang RiJia., et al (2013): Intravitreal triamcinolone versus Intravitreal bevacizumab for diabetic macular edema: a meta-analysis .Int $\mathbf{J}$ Ophthalmol; 6:546-52.

21. Diabetic Retinopathy Clinical Research (DRCR) Network, Elman MJ, Aiello LP, et al (2010). Randomized Trial Evaluating Ranibizumab Plus Prompt or Deferred Laser or Triamcinolone Plus Prompt Laser for Diabetic Macular Edema. Ophthalmology.; 117(6):1064-1077.

\begin{tabular}{|c|c|}
\hline \multicolumn{2}{|c|}{ Access this Article in Online } \\
\hline 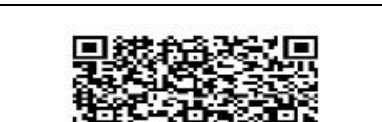 & $\begin{array}{l}\text { Website: } \\
\text { www.ijcrims.com }\end{array}$ \\
\hline 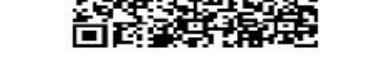 & \multirow{2}{*}{$\begin{array}{l}\text { Subject: } \\
\text { Medical Sciences }\end{array}$} \\
\hline Quick Response Code & \\
\hline
\end{tabular}

How to cite this article:

Khedr M M, Ghali A A and Gad M A. (2017). The combination of phacoemulsification surgery and intravitreal triamcinolone injection in patients with cataract and diabetic macular edema. Int. J. Curr. Res. Med. Sci. 3(6): 142-155. DOI: http://dx.doi.org/10.22192/ijcrms.2017.03.06.019 